\title{
Linguistic Methods to Detect Lies
}

\author{
Daoshan Ma1 ${ }^{*}$, Dong'ao Lin ${ }^{2}$ \\ ${ }^{1}$ Department of English, School of Foreign Languages, Tianjin Polytechnic University, Tianjin, China \\ ${ }^{2}$ City University of Hong Kong, Hong Kong, China \\ Email: :madaos@tom.com
}

Received 2 December 2015; accepted 17 December 2015; published 22 December 2015

Copyright (C) 2015 by authors and OALib.

This work is licensed under the Creative Commons Attribution International License (CC BY).

http://creativecommons.org/licenses/by/4.0/

(c) $\underset{\mathrm{EY}}{\mathrm{C}}$ Open Access

\begin{abstract}
The present manuscript mainly introduces three linguistic methods to detect lies, namely Handwriting Analysis, Voice Stress Analysis, and Non-Verbal Analysis and the application of these linguistic deception detection approaches in various fields, such as law enforcement, intelligence agencies, and forensic context. These major deception detection techniques are illustrated by examples based on graphology, psycho-physiological stress response, and non-verbal communication studies.
\end{abstract}

Keywords

Deception, Detection, Linguistics

Subject Areas: Linguistics, Psychology

\section{Introduction}

Lie detection, also known as deception detection, uses questioning techniques and technology to ascertain truth and falsehood in response (Wikipedia: "Lie Detection"). The previous studies of lie detection have been based on linguistic theories [1]-[12]. Some of these studies are mainly focused on verbal statement analysis [9]-[11] and written statement analysis [8] [12]. Others are dealing with how deception detection can be achieved through exploration of automatic methods [2]-[7]. The major detection techniques besides Statement Analysis ${ }^{\circledR}$ [1] [9] [11], which will be mentioned in this thesis, are based on graphology, psycho-physiological stress response, and non-verbal communication studies. The techniques of graphology, psycho-physiological stress response, and non-verbal communication studies have been widely used in law enforcement in crime investigation, intelligence agencies, forensic trials, and other fields.

\section{Handwriting Analysis}

The study of handwriting is also referred to "graphology", which is "the analysis of the physical characteristics ${ }^{*}$ Corresponding author.

How to cite this paper: Ma, D.S. and Lin, D.A. (2015) Linguistic Methods to Detect Lies. Open Access Library Journal, 2: e2173. http://dx.doi.org/10.4236/oalib.1102173 
and patterns of handwriting purporting to be able to identify the writer, indicating psychological state at the time of writing, or evaluating personality characteristics” (Wikipedia). The quotation explained what is graphology (or handwriting) and modifies the definition by using "purporting", because so far it has been an empirical study and no scientific theory to support its validity.

Despite of the lack of academic support, it still serves as an aid in forensic and law enforcement fields. Here are some typical examples quoted from the Yahoo website:

1) It is generally accepted that large handwriting indicates extrovert personality while the small one implies the personality of being introvert.

2) The letter "O”: An honest person will write this letter without additional lines or loops. In contrast, a loop on the left side of the letter indicates that the writer withholds something from himself and a loop on the right represents the he hides secrets from others as Figure 1 shows.

Figure 2 shows that there is a kind of double loops that appears inside the letter as the first "O" in the Figure 2 presents and overlapping loops as the second " $\mathrm{O}$ " in the Figure 2 presents. They are all strong indications of a pathological liar.

Some may argue that they are taught to have a cursive writing according to the writing sample. (Usually, cursive writing is popular in Chinese classroom.) As Figure 3 shows:

However, Figure 4 shows a sample of cursive handwriting in reality:

3) A most notorious handwriting is called "Felon's Claw" which "is created when a person makes a straight down-stroke that turns into a claw or hook" [9]. Figure 5 shows that people possess this type of handwriting can be very dangerous, for it is very likely that the person is self-destructive and may seek harm to others. If the claw angle is smooth, he may bring trouble in a passive way like detaining one's mail; if the angle is sharp, that means the person is physically aggressive.
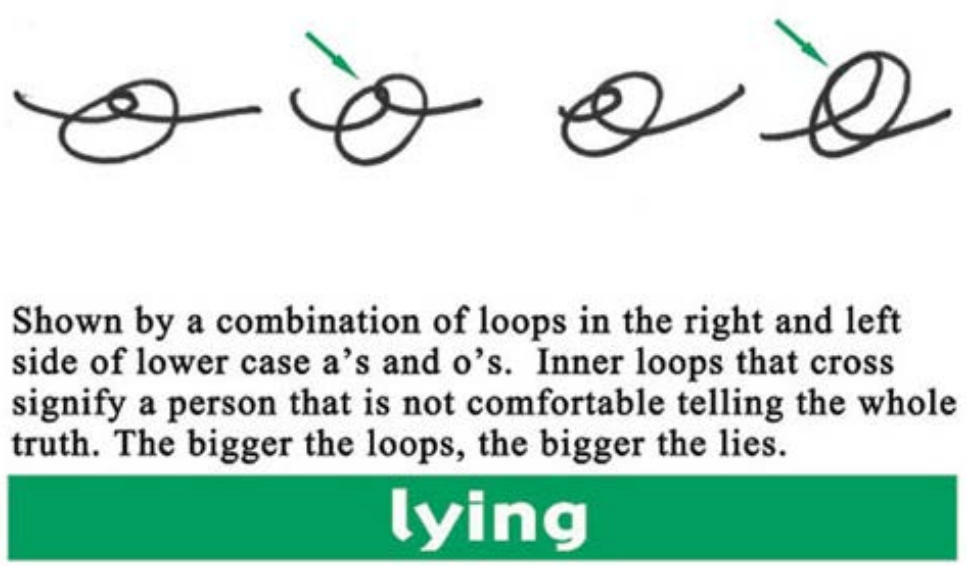

Figure 1. The lying loop (http://www.handwritinguniversity.com/members/weekly-newsletters/lying-loops).

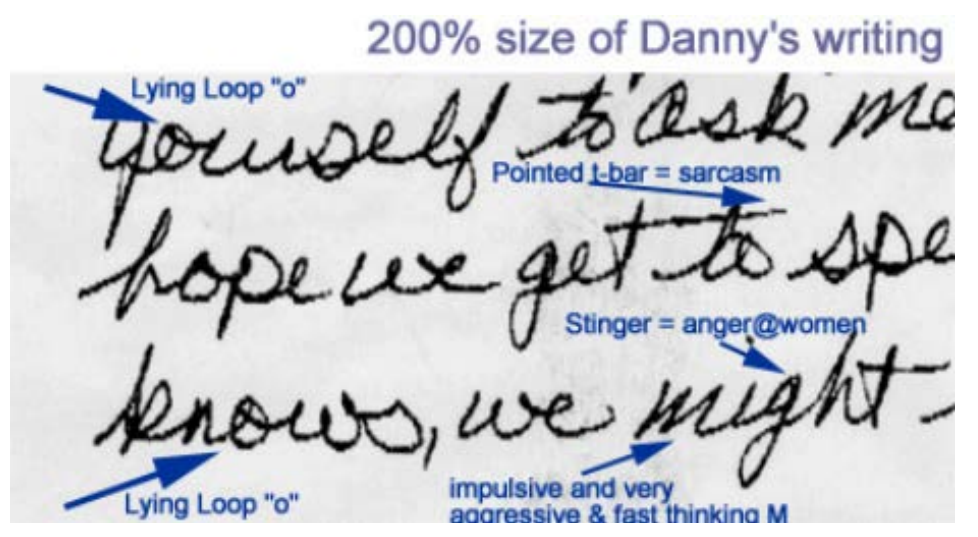

Figure 2. (https://hk.images.search.yahoo.com/search/images). 


\section{$A B C D E F \& H$ \\ $\&<\mathcal{L} \pi \pi \theta 2 R$ \\ \& $\mathcal{U}$ vwx yz}

Figure 3. Cursive handwriting sample (https://hk.images.search.yahoo.com/search/images).

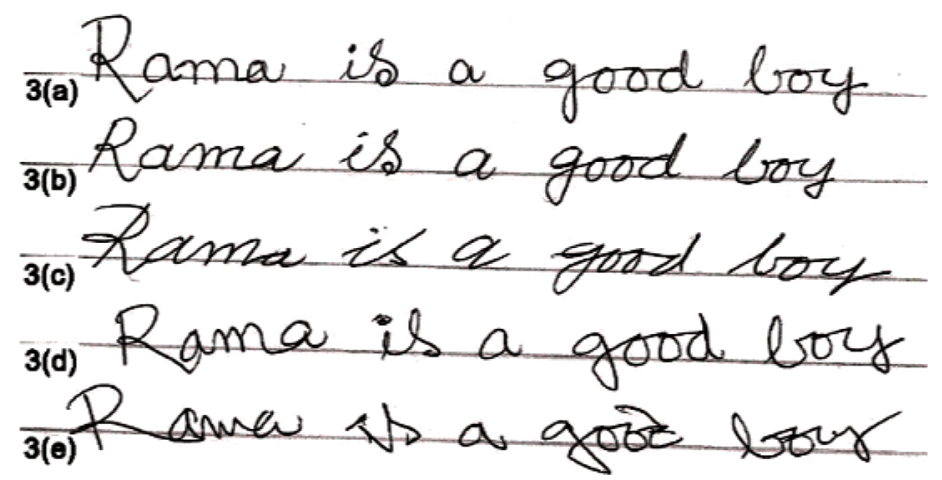

Figure 4. Cursive handwriting in reality (https://hk.images.search.yahoo.com/search/images).

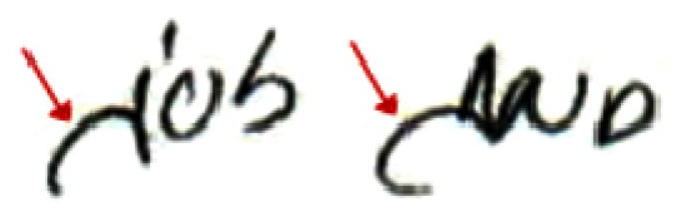

Figure 5. Felon’s claw (https://hk.images.search.yahoo.com/search/images).

4) Word Spacing: Experience shows that people with narrow word spacing is relatively insecure and want to be surrounded by their social group while wide spacing indicates the person keeps distance from others. In deception detection, a sudden pause in a sentence, e.g. "I didn’t went to the store” implies a possibility of deception, because the writer is hesitating what to say or how to say.

Those examples display a glimpse of deception detection techniques in graphology. And they are well applied in some crime investigations, for instance, Phillip Garrido Kidnapping Case in 1991. Thus, this technique has the capacity to provide clues in the real-life investigation.

\section{Voice Stress Analysis}

"Voice Stress Analysis (VSA) systems are marketed as computer-based system capable of measuring stress in a person's voice as an indicator of deception” [13]. This technique was developed by three retired U.S. Army officers in 1970s. It generally can be understood that the machine consists of three components: a tape recorder, microphone, and the most state-of-art part, a fast-speed computer with a special designed VSA software. The suggestion is given that a sufficient deceptive stress database with ground truth is needed to enhance its credibility.

According to Dr. John Hansen of the University of Colorado, voice stress is caused by factors that introduce variability into the speech production process, which includes duration, glottal source factors, pitch distribution, spectral structure and intensity.

VSA has one merit which distinguishes the other techniques that no human intervene is involved during the deception detection because the computer conducts the whole process and gives the result. In other words, the 
accuracy will not be influenced by human biases.

Comparison, or even competition, is always made between VSA and Polygraph, another cutting-edge technology in deception detection, measuring a person's blood pressure, breathing rate, pulse and perspiration, rather than vocal tremor. Each of their associations has issued reports to claim the inaccuracy of its rivals. However, regardless of the arguments about effectiveness, VSA is less costly and easier to conduct than Polygraph. There is no physical attachment and restricted answer of "yes" or "no" is not required. "Purportedly, according to some vendors, any spoken word or even a groan, whether recorded, videotaped, or spoken in person, with or without the speaker's knowledge, are acceptable inputs...” [13].

\section{Non-Verbal Analysis}

\subsection{Human Behaviors}

To detect deception through human behaviors, a study called "kinesics" has to be involved. Kinesics is an unordinary term, but known to people as "body language", which focuses on the observation of facial expressions, eye contact, body posture, gesture, and the using of space. (Notice that it should not be confused with "Sign Language”, which is a sort of full language with a complex grammar system).

Kinesics or body language study has great significance in deception detection because the research shows 93\% of human communication is non-verbal; the "language" (actually "verbal language") people usually focus on or refer to merely takes up 7\%. It means that there is a secret body language world waiting to be decoded.

It is common to see when a student is asked to answer a question in the classroom, he or she will unconsciously scratch his/her neck or back side of his/her back head, rub his/her nose, and sometimes a cough (most of the time it is believed fake) is accompanied. The chances are the student fails to give the answer. Why there are such movements? It is because his/her "internal stress will cause a tingling sensation in the tissues around the neck" [9] and a fake cough will disguise the person's uneasiness as well as install some time to make the next move. Those situations also appear in deception scenes.

Here are two classic examples (All illustrates from Yahoo Website):

1) Crossed-Arms-on-Chest: Figure 6 shows that this is obviously a universal posture that in a strange or unpleasant situation, one's arms are folded behind the chest and usually this person will not appear to be happy. The reasons to explain may have several. Some experts or book authors explain it happens when the person disagrees with someone, feels uneasy, or annoyed so that a physical barrier is built to tell he or she is ready to defense him/herself. But no matter what interpretations, one thing is clear that "as long as someone holds an arms-folded position, a negative attitude will persist” [14].

2) Eye Movements: Eyes can tell a lot of information, for example, if a person is happy, sad, inspired, or touched. In deception detection the looking direction of eyes is significant. Figure 7 shows that when a person is

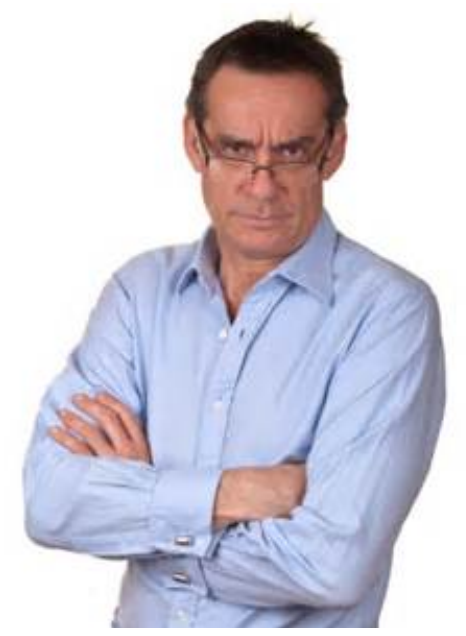

Figure 6. Crossed-arms position (https://hk.images.search.yahoo.com/search/images;_ylt=A2oKmLcphkVWWlUAMauzygt.; ylu=X3oDMTByYmJwODBk BGNvbG8Dc2czBHBvcwMxBHZ0aWQDBHNlYwNzYw--?p=Crossed-Arms+Position\&fr=yfp-t-900-hk). 


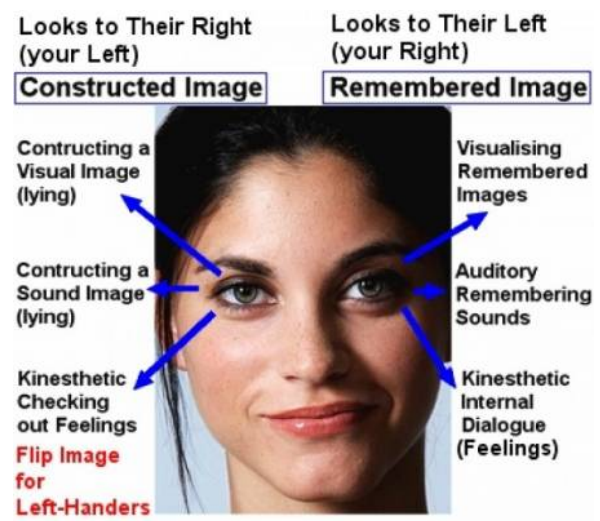

Figure 7. Eye movements (https://hk.images.search.yahoo.com/images/view).

asked to recall a certain image from his memory, e.g. the picture on the news headline this morning, he will look up to his left and when the object is sound, e.g. his favorite song, he will look horizontally to his left. When asked to create or imagine a certain image, the person will look up to his right, and when asked sound, to his horizontal right. If the person does it in an opposite way, for instance, when asked what he did last night, he answers by looking up to his right. This indicates he is lying because as it was mentioned above, a truthful person will recall things from his memory instead of his imagination. People looking down to their left means they are deep in thought and down to their right represents that they are recalling feelings. All the indications are opposite if the subject is a left-handed person.

To sum up, the key to detect deception through body language is to establish normal behavior movements and to examine any strange change from them.

\subsection{Polygraph}

Here comes the great competitor of Voice Stress Analysis (VSA). This device or technology is supported by the belief that the deceiver will produce physiological response and tracing down these changes could find evidence of deception. The person who takes the test will be asked some simple question first, such as what is his name, what is his cell phone number etc. The response is restricted to "yes" or "no". While answering these questions their physiological responses, e.g. blood pressure, plus, respiration and skin conductivity will be recorded as a normal range. Then critical questions contributing to the investigation will be asked to see if the person has changes beyond the range [15]-[17]. Although the process is based on questioning, Polygraph is categorized into the Non-Verbal branch because it works upon electronic technology and the study of physiology.

"Law enforcement agencies across the United States have long relied on this technique, but the since the federal Employee Polygraph Protection Act in 1988 and costly budget of the equipment and training fee, very few local, county, or state still uses the technique except in some severe criminal cases” [15].

Polygraph proponents hold strong opinions against VSA. The brochure published by the American Polygraph Association \& the American Association of Police Polygraphists shows various statistics and journals to criticize the accuracy of VSA. However, Polygraph is not definitely reliable. In Connecticut Wood Chipper Case in 1986, the murderer Richard Craft passed the polygraph tests more than once because of his trained former CIA agent background.

\section{Applied Fields}

Almost all deception detection knowledge is drawn from real-life practice and its ultimate goal shall be the application back to life.

\subsection{Law Enforcement}

The first applied field on the top of the list should be law enforcement agencies. As a matter of fact, techniques such as Statement Analysis are developed from the police officers with years of working experience. The standard process to investigate a suspect will be a request of statement, asks him to write down all the events that 
happened during a period of time, and then based on the written statement, the suspect will be given an interview which will be recorded for further investigation and re-evaluation. At that point, VSA will possibly be applied.

\subsection{Intelligence Agencies}

This is a general term and agencies like this may conclude FBI (law enforcement branch), CIA, NSA (National Security Association), and other intelligence branches under the command of United States Armed Forces. Their responsibility is to prevent any threat, like terrorism, to the homeland security or people's lifestyle. Those agents are trained with expertise to carry out the investigation or interrogation through linguistic deception detection skills. In some cases, polygraph is used to evaluate the information.

\subsection{Forensic Context}

In any democratic society, a public hearing will be held before the formal prosecution. The public is able to see the whole investigation via social media. Therefore, any official or civilian can detect deception through the suspect's statement. In the February of 2012, George Zimmerman, Florida, was on duty of the neighborhood watch. He fatally shot a seventeen-year-old African American male Trayvon Martin. Then a national focused trial about whether Zimmerman committed murder or he was in self-defense was hold. Almost a year later he was controversially released innocent. During the trial Zimmerman was asked to have Voice Stress Analysis Test. The videotape is open to the public. However, deception is not the main issue in this case.

\subsection{Other Fields}

Linguistic deception detection approaches can also be applied in everyday life:

-Business Negotiation;

-Job/School Admission Interview;

-CV (Curriculum Vitae), PS (also known as Statement of Purpose), Email, and Other Documents Detection; -Audio Conference;

-Online Dating, along with other potential deception in computer mediated texts e.g. fake reviews posted on the online shopping websites.

\section{Conclusion}

Deception can be detected through linguistic means. Three of these means besides Statement Analysis can be handwriting analysis, voice stress analysis and non-verbal analysis. This thesis deals with how these techniques can be used to detect lies. It is shown that people really mean what they say and lies can be thus detected by handwriting analysis, voice stress analysis and non-verbal analysis. The techniques of graphology, psychophysiological stress response, and non-verbal communication studies, briefly discussed in this thesis, have been widely used in law enforcement in crime investigation, intelligence agencies, forensic trials, and other fields.

\section{Acknowledgements}

Daoshan Ma and Dong'ao Lin would like to thank the colleagues at Tianjin Polytechnic University for the suggestions and comments on the thesis.

\section{References}

[1] Ma, D.S. and Lin, D.A. (2015) Statement Analysis of Deception Detection. Open Access Library Journal, 2: e1975. http://dx.doi.org/10.4236/oalib.1101975

[2] De Paulo, B.M., Lindsay, J.J., Malone, B.E., Muhlenbruck, L., Charlton, K. and Cooper, H. (2003) Cues to Deception. Psychological Bulletin, 129, 74-118. http://dx.doi.org/10.1037/0033-2909.129.1.74

[3] Ekman, P. (2001) Telling Lies: Clues to Deceit in the Marketplace, Politics, and Marriage. W.W. Norton, New York.

[4] Fitzpatrick, E. and Bachenko, J. (2009) Building a Forensic Corpus to Test Language-Based Indicators of Deception. Language and Computers, 71, 183-196.

[5] Fornaciari, T. and Poesio, M. (2013) Automatic Deception Detection in Italian Court Cases. Artificial Intelligence and 
Law, 21, 303-340. http://dx.doi.org/10.1007/s10506-013-9140-4

[6] Hancock, J.T., Curry, L.E., Goorha, S. and Woodworth, M. (2007) On Lying and Being Lied to: A Linguistic Analysis of Deception in Computer-Mediated Communication. Discourse Process, 45, 1-23. http://dx.doi.org/10.1080/01638530701739181

[7] Newman, M.L., Pennebaker, J.W., Berry, D.S. and Richards, J.M. (2003) Lying Words: Predicting Deception from Linguistic Styles. Personality and Social Psychology Bulletin, 29, 665-675. http://dx.doi.org/10.1177/0146167203029005010

[8] Strapparava, C. and Mihalcea, R. (2009) The Lie Detector: Explorations in the Automatic Recognition of Deceptive Language. Proceedings of the ACL-IJCNLP 2009 Conference Short Papers, Singapore, 4 August 2009, 309-312.

[9] McClish, M. (2012) Don’t Be Deceived: The Definitive Book on Detection Deception. 2nd Edition, The Marpa Group, Inc., Winterville.

[10] Frank, M.G., Menasco, M.A. and O’Sullivan, M. (2008) Human Behavior and Deception Detection. In: Voeller, J.G., Ed., Handbook of Science and Technology for Homeland Security, Vol. 5, John Wiley \& Sons, Inc., Hoboken. http://dx.doi.org/10.1002/9780470087923.hhs299

[11] Adam, S.H. (1996) Statement Analysis: What Do Suspects’ Words Really Reveal? FBI Law Enforcement Bulletin, 65, 12-20.

[12] Toma, C.L. and Hancock, J.T. (2012) What Lies Beneath: The Linguistic Traces of Deception in Online Dating Profiles. Journal of Communication, 62, 78-97. http://dx.doi.org/10.1111/j.1460-2466.2011.01619.x

[13] Haddad, D., Walter, S., Ratley, R. and Smith, M. (2012) Investigation and Evaluation of Voice Stress Analysis Technology. U.S. Department of Justice.

[14] Pease, A. and Pease, B. (2004) The Definitive Book of Body Language. Pease International, Australia.

[15] Palmatier, J.J. (2011) Credibility Assessment: The CVSA, Polygraph, and Turstech/Vericator Voice Analysis Technologies. http://www.nemesysco.com/JJP-research Full.pdf

[16] Palmatier, J.J. and Rovner, L. (2015) Credibility Assessment: Preliminary Process Theory, the Polygraph Process, and Construct Validity. International Journal of Psychophysiology, 95, 3-13. http://dx.doi.org/10.1016/j.ijpsycho.2014.06.001

[17] Palmatier, J.J. and Rovner, L. (2015) Rejoinder to Commentary on Palmatier and Rovner (2014): Credibility Assessment: Preliminary Process Theory, the Polygraph Process, and Construct Validity. International Journal of Psychophysiology, 95, 31-34. http://dx.doi.org/10.1016/j.ijpsycho.2014.11.009 